\title{
Partial splenectomy in the era of minimally invasive surgery: the current laparoscopic and robotic experiences
}

\author{
Alexandre Balaphas $\cdot$ Nicolas C. Buchs $\cdot$ \\ Jeremy Meyer • Monika E. Hagen • \\ Philippe Morel
}

Received: 29 October 2014/Accepted: 13 February 2015/Published online: 5 March 2015

(C) Springer Science+Business Media New York 2015

\begin{abstract}
Background Partial splenectomy (PS) is a spleen-preserving technique that is applied as a result of trauma, focal lesions or hematological conditions. Despite the improvement of laparoscopic techniques within the past several decades, minimally invasive PS has remained a marginal technique that has not been well evaluated. Our objective was to provide an update on the indications and the feasibility of this procedure.

Methods The MEDLINE database (PubMed) was searched, and all relevant articles that involved a true minimally invasive PS (i.e., segmental or lobar devascularization of the spleen with parenchymal transection) were included. The search was conducted until the 31st of March 2014. Demographic data, operative indications, estimated blood losses, operative times, conversion rates and complications were extracted from the included articles and were summarized for discussion.

Results Out of the 195 publications that were retrieved, 33 were included, which were mainly case reports and case series that represented a total of 187 patients. There were 37 men, 33 women and 117 patients of unknown gender. The mean age of the patients was ranged from 6 to 58 years. The mean total operative time was between 70 and $216 \mathrm{~min}$ for conventional laparoscopy and between 108 and $120 \mathrm{~min}$ for the robotic approach. For most studies, the mean estimated blood loss was minimal. The
\end{abstract}

A. Balaphas $(\varangle) \cdot$ N. C. Buchs · J. Meyer .

M. E. Hagen - P. Morel

Division of Digestive and Transplantation Surgery, Geneva

University Hospitals, Rue Gabrielle-Perret-Gentil 4,

1211 Geneva, Switzerland

e-mail: alexandre.balaphas@hcuge.ch complication rate was $5.36 \%$ for conventional laparoscopy and $5.56 \%$ for the robotic approach.

Conclusion The outcomes of minimally invasive PS were favorable and comparable to those of the open technique according to the literature. This procedure may constitute an attractive alternative to the open technique for selected cases. Moreover, a robotic approach might be an interesting technical option, but additional research is needed before any definitive conclusions can be drawn.

Keywords Partial splenectomy - Laparoscopic Robotic · Outcomes · Complications · Augmented reality
Abbreviations
LPS Laparoscopic partial splenectomy
OPSI Overwhelming post-splenectomy infection
PS Partial splenectomy
RPS Robotic partial splenectomy
SSPS Single-site access partial splenectomy

The main concern following total splenectomy is overwhelming post-splenectomy infection (OPSI), a severe type of sepsis that is caused by encapsulated bacteria and triggered primarily by Streptococcus pneumoniae, Neisseria meningitidis and Haemophilus influenzae type b in splenectomized and hyposplenic individuals [1]. After total splenectomy, the lifetime risk of OPSI increases up to $5 \%$, with a dramatic rise to 200 times the risk of subsequent mortality compared with the reference population [2]. Moreover, the 10-year risk for hospital admission for infections of various severities is $33 \%$ [3].

In addition, recent studies have demonstrated that iatrogenic asplenism may be associated with increased risks 
of pulmonary hypertension, arteriosclerosis and coronary artery disease $[4,5]$. Moreover, reactive thrombocytosis was shown to elicit thrombosis of the spleno-mesaraic trunk $[6,7]$, particularly in patients who suffer from hematological pathologies [8].

These risks have led to calls for an approach that limits the extent of the splenectomy or that spares some splenic function. A more conservative surgical approach has thus been advocated whenever possible, either for elective cases or for trauma situations. Depending on the indications, the partial embolization of the spleen constitutes an attractive alternative to the surgical approach. However, this technique exhibits many complications, such as abscess formation, spontaneous splenic rupture and post-embolization syndrome, which affect all patients with various severities (e.g., fever, abdominal pain and vomiting) [9]. For surgical cases, partial splenectomy (PS) constitutes the method of choice to remove splenic lesions and to decrease splenic size while preserving organ function [10]. After such a procedure, only a transient depression of immunity is observed [3]. As an alternative, auto-transplantation of a splenic remnant was investigated during the eighties, but the transplant was shown to be poorly functional $[3,11$, 12].

Open segmental splenectomy was mentioned by Christo [13] and PS has been formerly recognized since a report by Morgenstern et al. [14]. A laparoscopic approach was first performed by Poulin et al. [15] for a trauma patient with prior selective embolization of an active hemorrhage. Its indications have since been extended to cystic diseases, solid tumors, abscesses, symptomatic splenic ischemia, vascular abnormalities and hematological pathologies such as thalassemia and spherocytosis.

While minimally invasive splenectomy is now recognized as the gold standard for most total splenectomy procedures [16], evidence is still lacking with regard to its role in partial PS. A recently published review of the literature that focuses on laparoscopic PS has suggested that the technique is easier to perform with a laparoscopic approach compared to an open one [17]. The objective of the present review is to provide an update on this particular topic and to implement the promising implications of new surgical technologies, such as single-site and robotic surgeries.

\section{Methods}

A thorough literature search was conducted within the MEDLINE database (PubMed) for articles related to PS that were performed either by conventional laparoscopy (laparoscopic PS-LPS) or by a robotic approach (robotic
PS-RPS). The following search terms were used: laparoscopic or robotic, associated with PS, hemisplenectomy, subtotal splenectomy or near total splenectomy. The references of identified articles were screened for studies related to the subject but that were not identified by the MEDLINE search. All articles in English, French and German that were published no later than the 31st of March 2014 were considered for inclusion. Articles were excluded for the following reasons: No full text was available, they were duplicate publications of the same results, they contained mixed data on the open and laparoscopic techniques but did not allow the possibility to distinguish between them, and the PS was performed as part of another procedure or if the procedure did not involve the transection of the splenic parenchyma or its devascularization (e.g., cystectomy or peeling of the cyst wall, radiofrequency alone, aneurysm clipping, cyst puncture, unroofing or marsupialization). Doubtful cases were resolved by a consensus between the coauthors.

The following data were extracted from the included studies: country of the main author, mean age, gender, surgical indications, mean estimated blood loss, mean operative time, complications related to surgery and conversion rate. Blood loss was considered minimal if $<150 \mathrm{ml}$ and indicated otherwise. All continuous variables were rounded to the nearest whole number. Complications that required perioperative blood transfusions were detailed.

\section{Results}

Types of studies

One hundred and ninety-five articles were identified by the keywords search, and thirty-three were included after a review by the co-authors of this manuscript, as illustrated in Fig. 1. Table 1 summarizes the baseline characteristics of the included studies and the particularities of the study populations. The publications were essentially case reports or cases series, and a few cohort studies including one study that compared LPS to RPS [10]. Most of them were published recently, and therefore, they highlighted the recent developments of minimally invasive PS.

Patient demographics

The included studies reported a total of 187 cases of PS. LPS was performed in 168 patients, single-site access PS (SSPS) in one patient and RPS in 18 patients. A total of 37 men, 33 women and 117 patients of unknown gender were included in these studies. The mean age ranged from 6 to 58 years. 


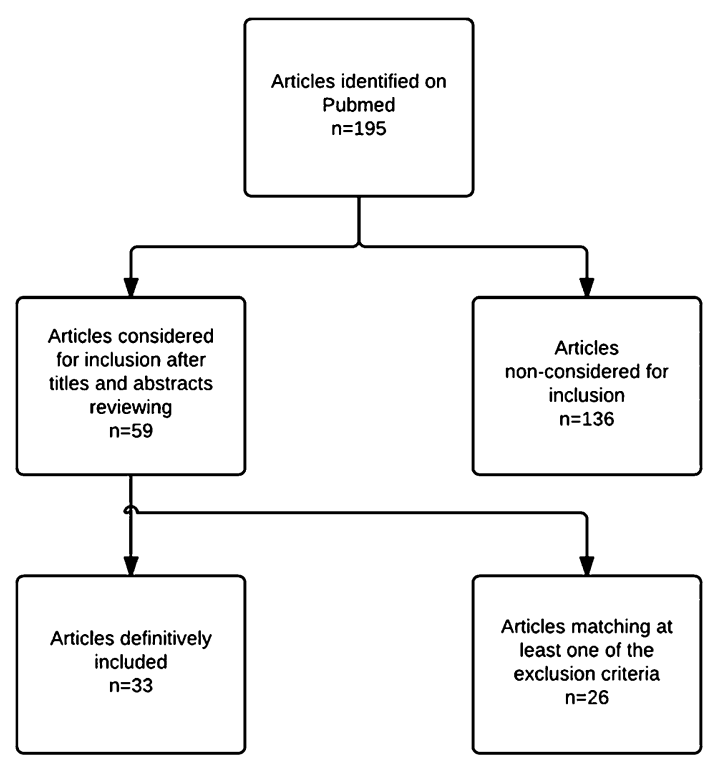

Fig. 1 Flowchart of the inclusion process

\section{Indications}

LPS was primarily performed for hereditary spherocytosis in 87 patients $(51.8 \%$ ), for non-parasitic cysts in 46 (27.3\%) patients and for vascular malformations (e.g., hemangioma, hemolymphangioma and hamartoma) in 13 $(7.7 \%)$ patients. Other indications are listed in Table 1. Similarly, the main indications for RPS were hereditary spherocytosis in ten patients (55.6\%) and parasitic hydatid cysts in four $(22.2 \%)$ patients. SSPS was only reported once for a patient with an epidermoid cyst.

\section{Surgical techniques}

\section{Conventional laparoscopy}

In seven articles, the patients were placed in a supine position (anterior approach), and in 17 articles, the patients were placed in a lateral or semilateral position. For the remaining publications, the position of the patient position was not described. In the included articles, the number of ports varied from 3 to 5 .

For almost all cases, the procedure began with the dissection of the spleen from its attachments. Unlike the open approach, only the portion to be resected was mobilized and detached. The vascular supply was then identified, and the organ was devascularized according to the segments that were to be preserved. This step was performed through the sectioning of the vessels with or without prior clipping. In order to perform the sectioning of the vessels, some authors used a vascular stapler, whereas others used energy-based devices, such as Ligasure (Covidien, Dublin,

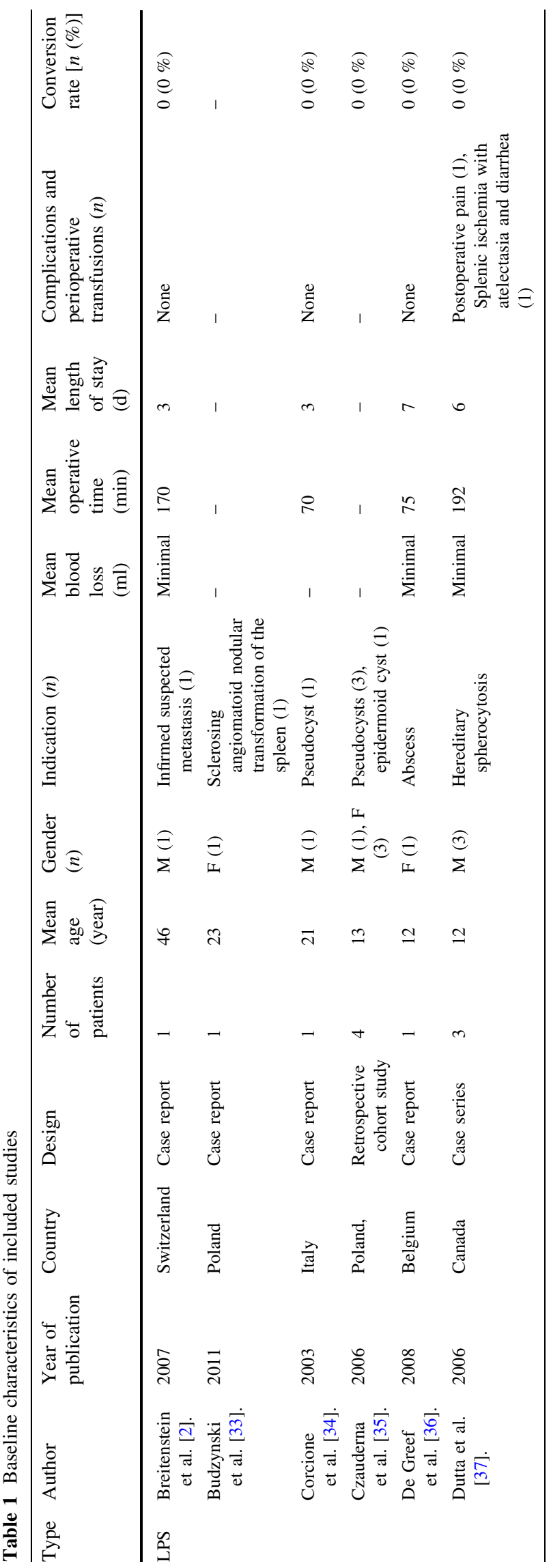




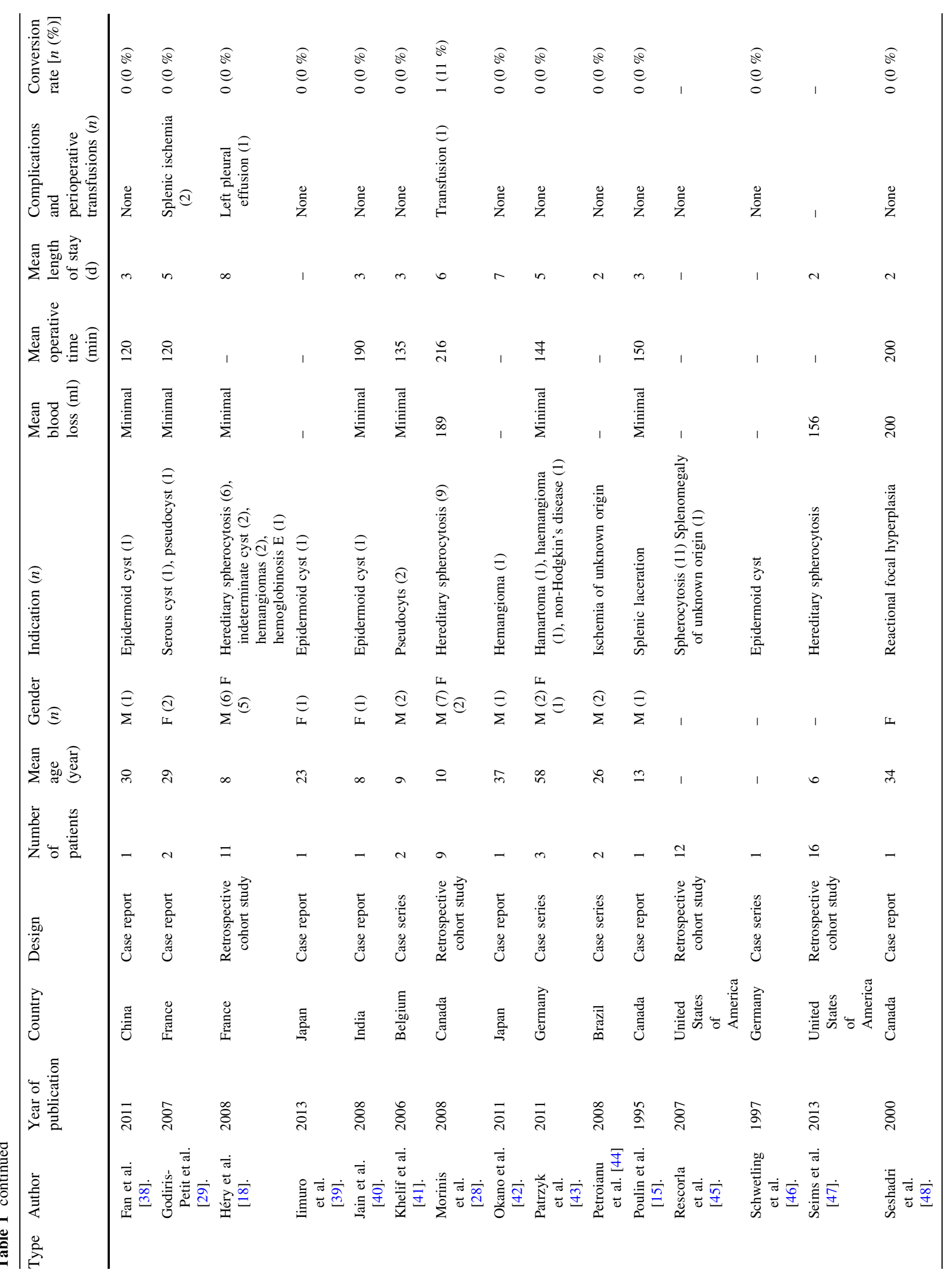




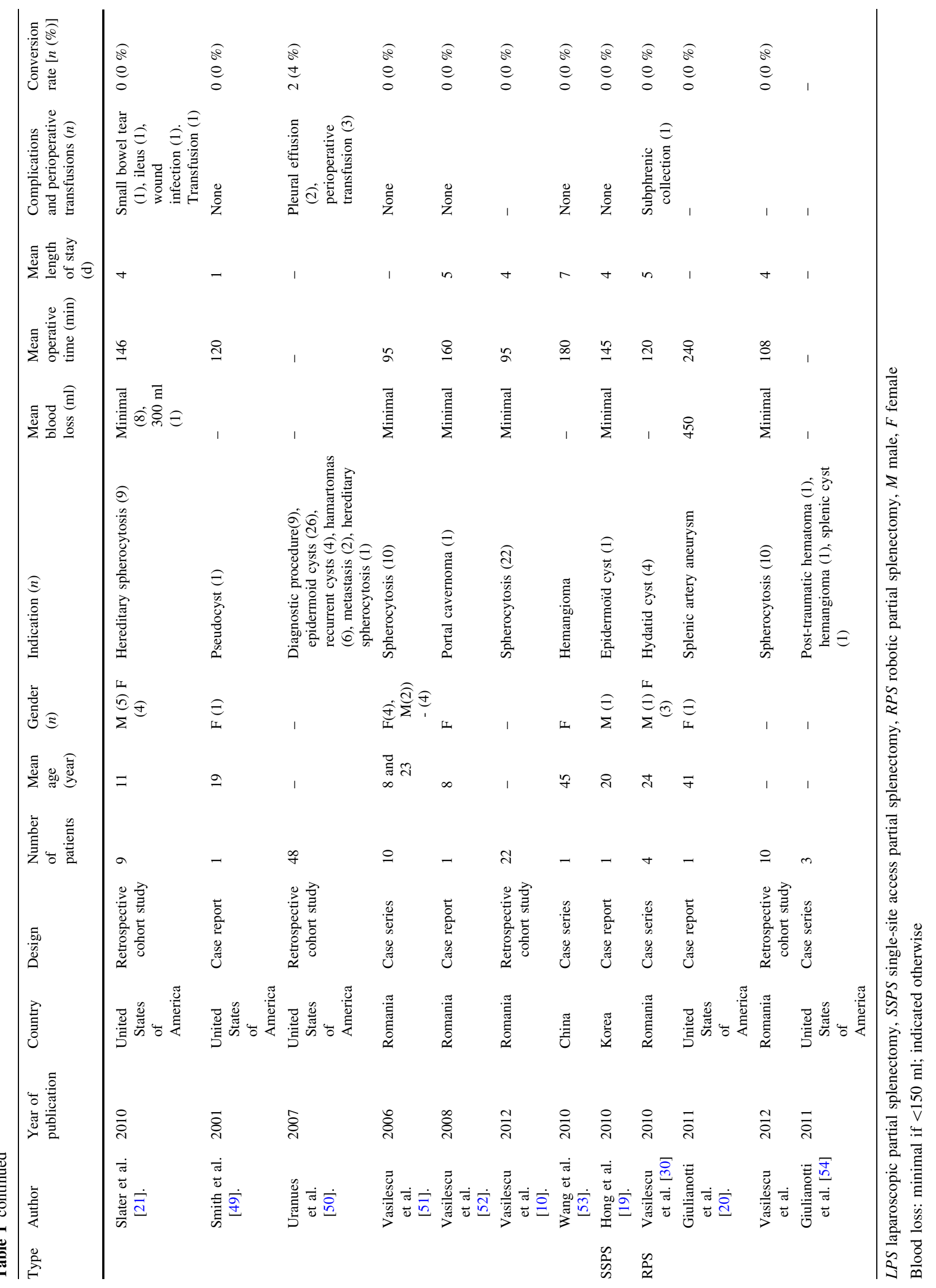


Ireland) or Harmonic Ultrasonic (Ethicon Endo-Surgery Inc, Somerville, NJ, USA).

The majority of surgeons then transected the spleen $5 \mathrm{~mm}$ or more above the demarcation line for safety reasons and used a large range of devices, such as vascular staplers, monopolar diathermy, ultrasound devices (Harmonic Ultrasonic) or Ligasure. Hemostasis was performed on the resection line with hemostatic products [e.g., fibrin glue, Tachocomb/Tachosyl (Takeda Pharma AG, Osaka Japan), Surgicel (Ethicon Endo-Surgery Inc, Somerville, $\mathrm{NJ}$ )], bipolar, argon beam (ConMed, Utica, NY) or monopolar diathermy. Some surgeons then completed the procedure by securing the splenic remnant to avoid torsion and necrosis. Hery et al. [18] even stitched the splenic capsule to the abdominal wall.

According to the described techniques and segmental anatomy of the spleen [12], four types of splenic segmentations were identified. We propose the following classification based on the remnant splenic pedicle (Fig. 2; Table 2). In techniques $\mathrm{A} 1$ and $\mathrm{A} 2$, the segmental hilar vessels were allowed to remain with the splenic remnant. The spleen was devascularized through the sectioning or clipping of the hilar vessels from the upper [A2] or the lower pole [A1] depending on the localization of the lesions or on the decision of the surgeon in the case of splenomegaly. In technique $\mathrm{B}$, short vessels were the sole blood supply to a remnant upper splenic pole. Two or three gastric short vessels were generally sufficient to supply blood to the remnant spleen. In technique $\mathrm{C}$, the remnant spleen was supplied by the left gastro-epiploic vessels.

\section{Laparoscopy with single port access}

Hong et al. [19] performed a SSPS with a customized port composed of a surgical glove applied on an Alexis retractor (Applied Medical, Rancho, Santa Margarita, CA, USA). The patient was placed in a lateral position, and the procedure did not differ from that of the LPS described above.

\section{Robotic surgery}

The anterior and lateral positions were chosen equally by the authors. Either four or five ports were used, and this was dependent on the surgeon's decision to operate with the fourth robotic arm. The primary steps of this procedure
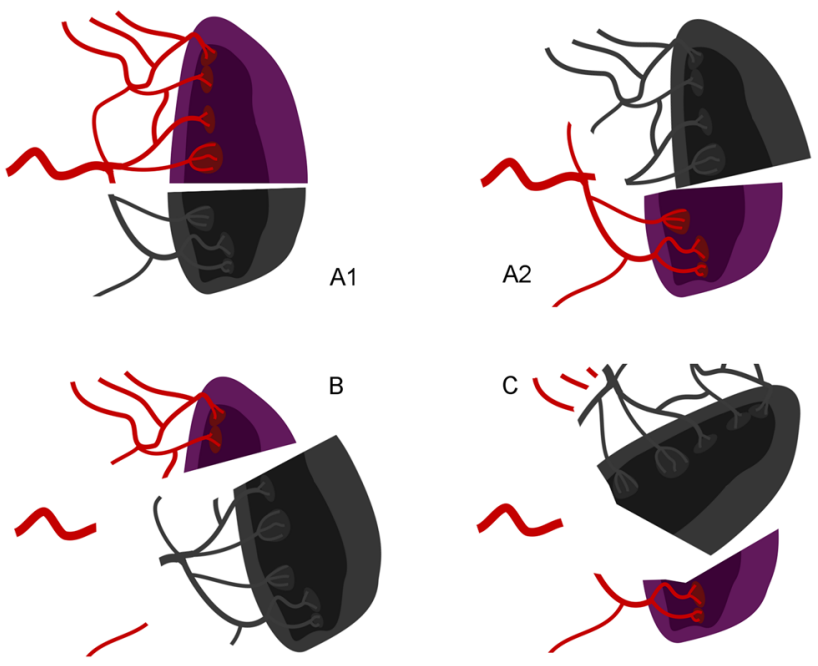

Fig. 2 Surgical techniques for partial splenectomy

were similar to the description given above. After transection, Giulianotti et al. [20] sewed the resection line with interrupted stitches for the purpose of hemostasis.

\section{Blood loss}

With respect to LPS, the blood loss was described as minimal in 12 studies with a total of 59 patients. Slater et al. [21] reported a maximal mean blood loss of $300 \mathrm{ml}$, which was due to a single patient who required a transfusion. The etiology of the blood loss was not reported in any of the studies. Blood loss was described as minimal for SSPS. The information with regard to blood loss was absent in two publications that involved RPS. Only Vasilescu et al. reported a minimal blood loss [10], and only Guilianotti et al. [20] reported a maximal loss of $450 \mathrm{ml}$ for a patient with a distal hilar aneurysm who did not require a transfusion.

\section{Operative time}

The mean total operative time ranged from 70 to $216 \mathrm{~min}$ for LPS, from 108 to $120 \mathrm{~min}$ for RPS and was $145 \mathrm{~min}$ for SSPS. A PS was sometimes followed by a cholecystectomy in cases of hereditary spherocytosis. Some authors reported the total operative time including this additional intervention, while others only reported the duration of time for the splenic surgery.
Table 2 Classification of partial splenectomy techniques

\begin{tabular}{lll}
\hline Technique & Segmental anatomy & Description \\
\hline A1 & Hilar vessels & Lower pole vessels sectioning, upper pole splenic remnant \\
A2 & Hilar vessels & Upper pole vessels sectioning, lower pole splenic remnant \\
B & Short vessels & Leaving 2-3 short vessels \\
C & Left gastroepiploic vessels & Leaving left gastro-epiploic vessels \\
\hline
\end{tabular}


Length of stay

The mean length of hospital stay was reported to vary from 1 to 8 days after LPS, from 4 to 5 days after RPS and was 4 days after SSPS.

\section{Complications}

Few major complications occurred in the surgical procedures of the included studies. After LPS, we found one intraoperative complication (small bowel tear) and nine postoperative complications, which represent a postoperative complication rate of $5.36 \%$. Postoperative complications consisted of the following: pleural effusion $(n=3)$, splenic remnant ischemia which was managed conservatively $(n=2)$, postoperative fever with ischemia of the remnant spleen and diarrhea which was managed with antibiotics $(n=1)$, ileus $(n=1)$, wound infection which was treated with antibiotics $(n=1)$ and postoperative pain of unknown etiology which required investigations $(n=1)$. Five patients required a perioperative transfusion $(2.98 \%)$. In the SSPS group, no complications or transfusions were reported, whereas one sub-phrenic abscess (complication rate of $5.56 \%$ ) was noted after RPS.

\section{Conversion rate}

Two conversions to an open procedure were reported during LPS because of uncontrolled bleeding. No conversion was reported in the SSPS and RPS groups. Moreover, there was no necessity for a total splenectomy in any patient.

\section{Discussion}

The technique of PS is based on the anatomy of the spleen, which is composed of 3-5 segments (Fig. 2). Segmental arteries arise from the polar arteries and constitute a terminal vascularization beyond the splenic hilum [22]. These polar arteries are also in connection with short vessels and the initial portion of the left gastro-epiploic artery. Interlobar and intersegmental planes are thus avascular [23]. Devascularization of the concerned segment creates a demarcation line where the transection can be performed with minimal blood loss.

The objective of PS is to remove a focal lesion or to retain the minimal functional splenic parenchyma in the case of hematologic conditions (mainly hereditary spherocytosis). In this type of pathology, anemia is the result of the associated hypersplenism, which promotes the accumulation of erythrocytes and their destruction in the spleen. A reduction in the volume of the spleen decreases the level of hemolysis while the immunologic function is preserved. There is a lack of consensus about the required minimal size of the remnant spleen. According to the literature, the size of the remnant that still provides a normal immune function varies from $5-10 \%$ to $25-30 \%$ of the total spleen [3]. In fact, growth of the remnant spleen after surgery may increase a $10 \%$ splenic remnant to a $25 \%$ remnant, and thus, there have been proposals to remove approximately $90 \%$ of the spleen. However, the continuous growth of the remaining spleen after surgery may be influenced by splenic growth factors that are present in hematological conditions, such as spherocytosis. These factors are most likely not present in the normal spleen with a focal lesion, and therefore, this rule cannot be generalized [5]. Hence, in the case of splenectomy for another etiology, a minimum of approximately $25 \%$ of the original spleen should be left in place [24-26].

According to the literature, open PS and LPS seem to share similarities with respect to blood loss, lengths of stay and complication rates, but the latter exhibits a longer total operative time compared with laparotomy [25-27]. However, LPS is likely associated with advantages that concern parietal aggression. In their pool of splenic procedures, Uranues and Alimoglu reported an incidence of $52 \%$ of incisional hernia after laparotomy after 2 years versus $3.2 \%$ after laparoscopy [17].

LPS was compared with laparoscopic total splenectomy by Morinis et al. [28] in a population of children with hereditary spherocytosis. LPS was associated with a statistically significant longer mean total operating time (216 vs. $157 \mathrm{~min}$ ), higher mean estimated blood loss (188 vs. $67 \mathrm{ml}$ ) and longer mean length of stay (6 vs. 3 days). However, these results need to be considered in light of the fact that the nine patients who were presented underwent surgery at the beginning of the surgeons' learning curves; in addition, some patients also underwent a laparoscopic cholecystectomy. The prolonged hospitalization was the result of sustained postoperative pain that was perhaps connected with potential ischemia of the splenic remnant. Moreover, these results do not reflect the advantages of PS, which often demonstrates long-term benefits, as we discussed before.

From a general point of view, the outcomes of minimally invasive PS were favorable. Blood loss was reported as minimal in most publications and only three patients required a transfusion after LPS. Two cases were converted to laparotomy for hemostatic control, but the blood losses were finally minimal. The mean total operative time was reported to have a very wide range. This finding might be explained by the frequent association of PS and cholecystectomy for hereditary spherocytosis. In one study of LPS, the mean length of hospital stay was 8 days with a range from 3 to 9 days. The authors reported 
that this prolonged hospitalization was the result of the systematic observation of the patients in the intensive care unit for a minimum of 2 days after surgery. No death and no major postoperative complication required re-intervention. Ischemia of the remnant spleen was one of the most frequent complications. This complication was associated with technique $\mathrm{B}$, as well as with technique $\mathrm{A}$, and therefore, our opinion is that this complication is not associated with a particular type of segmentation. Moreover, according to Godiris-Petit et al. [29], this observed ischemia could be subclinical and may be more common than we think and might explain some cases of prolonged postoperative pain. In the RPS group, there was only one subphrenic collection in four cases for a hydatid cyst [30].

According to Hollingsworth, the completion rate to total splenectomy for open PS is approximately $5 \%$ [31]. This finding needs to be compared with the $0 \%$ completion rate for minimally invasive approach $(n=187)$ that we found. This could reflect the rigorous case selection for LPS.

The main criteria that are used to avoid conversion from partial to total splenectomy are the size of the spleen and the morphology of the hilum. Splenic size also plays a role in the avoidance of mini-laparotomy for specimen extraction. Laparoscopy is ideal for small spleens with short and extrapedicular pancreatic tails [25], and although most reports neglected to mention the selection criteria, the cases were most likely selected according to these characteristics. Other selection criteria might include the BMI of the patients and prior abdominal surgery; however, such points were not discussed in the publications we included.

Patients who do not meet these criteria might be the best candidates for RPS [25]. RPS seems to constitute an interesting option for complex procedures, as demonstrated by Pietrabissa et al. and Giulianotti et al. [20, 32]. Beyond all the known advantages (e.g., endowrist technology, motion scaling, tremor reduction, stereoscopic vision), the robot allows for the superposition of augmented reality 3D reconstructions. The vascular supply of each segment of the spleen can therefore be predicted. The fusion of the vessels map and reality during the operation could help the surgeon to clip the appropriate vessel. This could save time, as the surgeon would know the vascular anatomy of the organ, which would eliminate the need to explore the whole hilum and to perform several clamping tests. Moreover, it is known that intracorporeal sutures are easier to perform with the seven degrees of freedom of the da Vinci robot (Intuitive Surgical Inc, Sunnyvale, CA, USA). The robot allows the stitching of the resection line and thus provides a good hemostatic control and precludes the use of hemostatic products. With the development of robotic surgery, spleen-sparing surgery assisted by augmented reality might become the new gold standard. Moreover, Vasilescu et al. directly compared LPS to RPS. They found a statistically significant difference in favor of RPS in terms of the mean estimated blood loss (35 vs. $90 \mathrm{ml})$ and the duration of the vascular dissection (20 vs. $15 \mathrm{~min})$. The mean total operative time was not significantly different between LPS and RPS.

While this review may describe new and encouraging outcomes, there are some limitations that deserve a comment. The data were not usable for direct comparisons; most notably because of the heterogeneity of the types of publications and the populations that were studied, the missing data and the small numbers of cases considered in the SSPS and RPS groups. However, this review also gives a hopeful overview on PS performed by conventional laparoscopy, by single port approach or by robotics. It establishes the feasibility of this approach and reports results that are more than favorable.

\section{Conclusion}

This review provides evidence that a laparoscopic approach constitutes an attractive alternative to the open technique for elective PS. Compared with the open technique, the outcomes are at least similar, except for the operative time which might be longer in conventional laparoscopy. Technically, LPS and RPS remain challenging and should be reserved for surgeons who are experienced in minimally invasive procedures.

PS could take advantage of new emerging technologies. Although robotic surgery incorporates augmented reality, it is still an experimental technique, but has shown potential for complex splenic procedures such as PS; however, this technique deserves further investigation.

Disclosures Drs. Alexandre Balaphas, Nicolas C. Buchs, Jeremy Meyer and Prof. Philippe Morel have no conflicts of interest or financial ties to disclose. Dr. Monika Hagen is a consultant for Intuitive Surgical International.

\section{References}

1. Hansen K, Singer DB (2001) Asplenic-hyposplenic overwhelming sepsis: postsplenectomy sepsis revisited. Pediatr Dev Pathol 4:105-121

2. Breitenstein S, Scholz T, Schafer M, Decurtins M, Clavien PA (2007) Laparoscopic partial splenectomy. J Am Coll Surg 204:179-181

3. Di Sabatino A, Carsetti R, Corazza GR (2011) Post-splenectomy and hyposplenic states. Lancet 378:86-97

4. Hoeper MM, Niedermeyer J, Hoffmeyer F, Flemming P, Fabel H (1999) Pulmonary hypertension after splenectomy? Ann Intern Med 130:506-509

5. Jais X, Ioos V, Jardim C, Sitbon O, Parent F, Hamid A, Fadel E, Dartevelle P, Simonneau G, Humbert M (2005) Splenectomy and chronic thromboembolic pulmonary hypertension. Thorax 60:1031-1034 
6. Hassn AM, Al-Fallouji MA, Ouf TI, Saad R (2000) Portal vein thrombosis following splenectomy. Br J Surg 87:362-373

7. Karakantza M, Theodorou GL, Mouzaki A, Theodori E, Vagianos C, Maniatis A (2004) In vitro study of the long-term effects of post-traumatic splenectomy on cellular immunity. Scand J Immunol 59:209-219

8. Rodeghiero F, Ruggeri M (2012) Short- and long-term risks of splenectomy for benign haematological disorders: should we revisit the indications? Br J Haematol 158:16-29

9. Kimura F, Ito H, Shimizu H, Togawa A, Otsuka M, Yoshidome H, Shimamura F, Kato A, Nukui Y, Ambiru S, Miyazaki M (2003) Partial splenic embolization for the treatment of hereditary spherocytosis. AJR Am J Roentgenol 181:1021-1024

10. Vasilescu C, Stanciulea O, Tudor S (2012) Laparoscopic versus robotic subtotal splenectomy in hereditary spherocytosis. Potential advantages and limits of an expensive approach. Surg Endosc 26:2802-2809

11. Alvarez FE, Greco RS (1980) Regeneration of the spleen after ectopic implantation and partial splenectomy. Arch Surg 115:772-775

12. Christo MC, DiDio LJ (1997) Anatomical and surgical aspects of splenic segmentectomies. Ann Anat 179:461-474

13. Christo MC (1959) Partial regulated splenectomies. Preliminary note on the first 3 cases operated on. Hospital 56:645-650

14. Morgenstern L, Shapiro SJ (1980) Partial splenectomy for nonparasitic splenic cysts. Am J Surg 139:278-281

15. Poulin EC, Thibault C, DesCoteaux JG, Cote G (1995) Partial laparoscopic splenectomy for trauma: technique and case report. Surg Laparosc Endosc 5:306-310

16. Habermalz B, Sauerland S, Decker G, Delaitre B, Gigot JF, Leandros E, Lechner K, Rhodes M, Silecchia G, Szold A, Targarona E, Torelli P, Neugebauer E (2008) Laparoscopic splenectomy: the clinical practice guidelines of the European Association for Endoscopic Surgery (EAES). Surg Endosc 22:821-848

17. Uranues S, Alimoglu O (2005) Laparoscopic surgery of the spleen. Surg Clin N Am 85:75-90

18. Hery G, Becmeur F, Mefat L, Kalfa D, Lutz P, Lutz L, Guys JM, de Lagausie P (2008) Laparoscopic partial splenectomy: indications and results of a multicenter retrospective study. Surg Endosc 22:45-49

19. Hong TH, Lee SK, You YK, Kim JG (2010) Single-port laparoscopic partial splenectomy: a case report. Surg Laparosc Endosc Percutan Tech 20:e164-e166

20. Giulianotti PC, Buchs NC, Coratti A, Sbrana F, Lombardi A, Felicioni L, Bianco FM, Addeo P (2011) Robot-assisted treatment of splenic artery aneurysms. Ann Vasc Surg 25:377-383

21. Slater BJ, Chan FP, Davis K, Dutta S (2010) Institutional experience with laparoscopic partial splenectomy for hereditary spherocytosis. J Pediatr Surg 45:1682-1686

22. Kimber C, Spitz L, Drake D, Kiely E, Westaby S, Cozzi F, Pierro A (1998) Elective partial splenectomy in childhood. J Pediatr Surg 33:826-829

23. Gamme G, Birch DW, Karmali S (2013) Minimally invasive splenectomy: an update and review. Can J Surg 56:280-285

24. Bader-Meunier B, Gauthier F, Archambaud F, Cynober T, Mielot F, Dommergues JP, Warszawski J, Mohandas N, Tchernia G (2001) Long-term evaluation of the beneficial effect of subtotal splenectomy for management of hereditary spherocytosis. Blood 97:399-403

25. Tchernia G, Bader-Meunier B, Berterottiere P, Eber S, Dommergues JP, Gauthier F (1997) Effectiveness of partial splenectomy in hereditary spherocytosis. Curr Opin Hematol 4:136-141

26. Stoehr GA, Stauffer UG, Eber SW (2005) Near-total splenectomy: a new technique for the management of hereditary spherocytosis. Ann Surg 241:40-47
27. Szczepanik AB, Meissner AJ (2009) Partial splenectomy in the management of nonparasitic splenic cysts. World J Surg 33:852-856

28. Morinis J, Dutta S, Blanchette V, Butchart S, Langer JC (2008) Laparoscopic partial vs total splenectomy in children with hereditary spherocytosis. J Pediatr Surg 43:1649-1652

29. Godiris-Petit G, Goasguen N, Munoz-Bongrand N, Cattan P, Sarfati E (2007) Laparoscopic partial splenectomy using the Harmonic Scalpel. Two case reports. J Chir 144:339-341

30. Vasilescu C, Tudor S, Popa M, Tiron A, Lupescu I (2010) Robotic partial splenectomy for hydatid cyst of the spleen. Langenbeck's Arch Surg 395:1169-1174

31. Hollingsworth CL, Rice HE (2010) Hereditary spherocytosis and partial splenectomy in children: review of surgical technique and the role of imaging. Pediatr Radiol 40:1177-1183

32. Pietrabissa A, Morelli L, Ferrari M, Peri A, Ferrari V, Moglia A, Pugliese L, Guarracino F, Mosca F (2010) Mixed reality for robotic treatment of a splenic artery aneurysm. Surg Endosc 24:1204

33. Budzynski A, Demczuk S, Kumiega B, Migaczewski M, Matlok M, Zub-Pokrowiecka A (2011) Sclerosing angiomatoid nodular transformation of the spleen treated by laparoscopic partial splenectomy. Wideochir Inne Tech Malo Inwazyjne 6:249-255

34. Corcione F, Cuccurullo D, Caiazzo P, Settembre A, Bruzzese G, Vittoria I, Cusano T (2003) Laparoscopic partial splenectomy for a splenic pseudocyst. Surg Endosc 17:1850

35. Czauderna P, Vajda P, Schaarschmidt K, Kalman A, Jainsch M, Engelis A, Lewicki K, Verebely T, Koltai J, Petersons A, Pinter AB (2006) Nonparasitic splenic cysts in children: a multicentric study. Eur J Pediatr Surg 16:415-419

36. De Greef E, Hoffman I, Topal B, Broers C, Miserez M (2008) Partial laparoscopic splenectomy for splenic abscess because of Salmonella infection: a case report. J Pediatr Surg 43:E35-E38

37. Dutta S, Price VE, Blanchette V, Langer JC (2006) A laparoscopic approach to partial splenectomy for children with hereditary spherocytosis. Surg Endosc 20:1719-1724

38. Fan H, Zhang D, Zhao X, Pan F, Jin ZK (2011) Laparoscopic partial splenectomy for large splenic epidermoid cyst. Chin Med J 124:1751-1753

39. Iimuro Y, Okada T, Sueoka H, Hai S, Kondo Y, Suzumura K, Fujimoto J (2013) Laparoscopic management of giant splenic true cyst with partial splenectomy: a case report. Asian J Endosc Surg 6:226-230

40. Jain P, Parelkar S, Shah H, Sanghvi B (2008) Laparoscopic partial splenectomy for splenic epidermoid cyst. J Laparoendosc Adv Surg Tech A 18:899-902

41. Khelif K, Maassarani F, Dassonville M, Laet MH (2006) Laparoscopic partial splenectomy using radiofrequency ablation for nonparasitic splenic cysts in two children. J Laparoendosc Adv Surg Tech A 16:414-417

42. Okano K, Kakinoki K, Suto H, Oshima M, Akamoto S, Hagiike M, Usuki H, Suzuki Y (2011) Hand-assisted laparoscopic partial splenectomy using an endopath monopolar sealer. Surg Laparosc Endosc Percutan Tech 21:e291-e294

43. Patrzyk M, Glitsch A, Hoene A, von Bernstorff W, Heidecke CD (2011) Laparoscopic partial splenectomy using a detachable clamp with and without partial splenic embolisation. Langenbeck's archives of surgery/Deutsche Gesellschaft fur Chirurgie 396:397-402

44. Petroianu A, Cabezas-Andrade MA, Berindoague Neto R (2008) Laparoscopic subtotal splenectomy. Surg Laparosc Endosc Percutan Tech 18:94-97

45. Rescorla FJ, West KW, Engum SA, Grosfeld JL (2007) Laparoscopic splenic procedures in children: experience in 231 children. Ann Surg 246:683-687 (discussion 687-688) 
46. Schwetling R, Anders S, Barlehner E (1997) Laparoscopic splenic surgery-report of 17 personal cases. Zentralbl Chir 122:291-294

47. Seims AD, Breckler FD, Hardacker KD, Rescorla FJ (2013) Partial versus total splenectomy in children with hereditary spherocytosis. Surgery 154:849-853 (discussion 853-845)

48. Seshadri PA, Poulin EC, Mamazza J, Schlachta CM (2000) Technique for laparoscopic partial splenectomy. Surg Laparosc Endosc Percutan Tech 10:106-109

49. Smith ST, Scott DJ, Burdick JS, Rege RV, Jones DB (2001) Laparoscopic marsupialization and hemisplenectomy for splenic cysts. J Laparoendosc Adv Surg Tech A 11:243-249

50. Uranues S, Grossman D, Ludwig L, Bergamaschi R (2007) Laparoscopic partial splenectomy. Surg Endosc 21:57-60
51. Vasilescu C, Stanciulea O, Tudor S, Stanescu D, Colita A, Stoia R, Coriu D, Colita A, Arion C (2006) Laparoscopic subtotal splenectomy in hereditary spherocytosis : to preserve the upper or the lower pole of the spleen? Surg Endosc 20:748-752

52. Vasilescu C, Stanciulea O, Popa M, Colita A, Arion C (2008) Subtotal laparoscopic splenectomy and esophagogastric devascularization for the thrombocytopenia because of portal cavernoma-case report. J Pediatr Surg 43:1373-1375

53. Wang J, Yu JC, Kang WM, Ma ZQ (2010) Laparoscopic partial splenectomy for giant hemangioma misdiagnosed as splenic cyst: a case report. Chin Med Sci J 25:189-192

54. Giulianotti PC, Buchs NC, Addeo P, Ayloo S, Bianco FM (2011) Robot-assisted partial and total splenectomy. Int J Med Robot Comput Assist Surg 7:482-488 